\title{
Milk intake and risk of mortality and fractures in women and men: cohort studies
}

\author{
(c) $\underset{1}{(1)(8)}$ OP OPEN ACCESS
}

\author{
Karl Michaëlsson professor ${ }^{1}$, Alicja Wolk professor ${ }^{2}$, Sophie Langenskiöld senior lecturer ${ }^{3}$, Samar \\ Basu professor ${ }^{3}$, Eva Warensjö Lemming researcher ${ }^{14}$, Håkan Melhus professor ${ }^{5}$, Liisa Byberg \\ associate professor ${ }^{1}$
}

${ }^{1}$ Department of Surgical Sciences, Uppsala University, SE-751 85 Uppsala, Sweden; ${ }^{2}$ Institute of Environmental Medicine, Karolinska Institutet, Stockholm, Sweden; ${ }^{3}$ Department of Public Health and Caring Sciences, Uppsala University, Uppsala, Sweden; ${ }^{4}$ Swedish National Food Agency, Uppsala, Sweden; ${ }^{5}$ Department of Medical Sciences, Uppsala University, Uppsala, Sweden

\begin{abstract}
Objective To examine whether high milk consumption is associated with mortality and fractures in women and men.

Design Cohort studies.

Setting Three counties in central Sweden.

Participants Two large Swedish cohorts, one with 61433 women (39-74 years at baseline 1987-90) and one with 45339 men (45-79 years at baseline 1997), were administered food frequency questionnaires. The women responded to a second food frequency questionnaire in 1997.
\end{abstract}

Main outcome measure Multivariable survival models were applied to determine the association between milk consumption and time to mortality or fracture.

Results During a mean follow-up of 20.1 years, 15541 women died and 17252 had a fracture, of whom 4259 had a hip fracture. In the male cohort with a mean follow-up of 11.2 years, 10112 men died and 5066 had a fracture, with 1166 hip fracture cases. In women the adjusted mortality hazard ratio for three or more glasses of milk a day compared with less than one glass a day was 1.93 (95\% confidence interval 1.80 to 2.06$)$. For every glass of milk, the adjusted hazard ratio of all cause mortality was 1.15 (1.13 to 1.17$)$ in women and 1.03 (1.01 to 1.04$)$ in men. For every glass of milk in women no reduction was observed in fracture risk with higher milk consumption for any fracture $(1.02,1.00$ to $1.04)$ or for hip fracture $(1.09,1.05$ to 1.13$)$. The corresponding adjusted hazard ratios in men were 1.01 (0.99 to 1.03 ) and 1.03 (0.99 to 1.07). In subsamples of two additional cohorts, one in males and one in females, a positive association was seen between milk intake and both urine 8-iso-PGF2a (a biomarker of oxidative stress) and serum interleukin 6 (a main inflammatory biomarker).

Conclusions High milk intake was associated with higher mortality in one cohort of women and in another cohort of men, and with higher fracture incidence in women. Given the observational study designs with the inherent possibility of residual confounding and reverse causation phenomena, a cautious interpretation of the results is recommended.

\section{Introduction}

A diet rich in milk products is promoted to reduce the likelihood of osteoporotic fractures. Milk contains 18 of 22 essential nutrients, including calcium, phosphorus, and vitamin D of especial importance for the skeleton. Intestinal uptake of these nutrients is enhanced by the enzymatic capacity to digest lactose into D-glucose and D-galactose by mutation in the lactase gene, a variant common in those with northern European ancestry. ${ }^{12}$ An intake of dairy foods corresponding to three or four glasses of milk a day has been suggested to save at least $20 \%$ of healthcare costs related to osteoporosis. ${ }^{3}$

A high intake of milk might, however, have undesirable effects, because milk is the main dietary source of D-galactose. Experimental evidence in several animal species indicates that chronic exposure to D-galactose is deleterious to health and the addition of D-galactose by injections or in the diet is an established animal model of aging. ${ }^{4-7}$ Even a low dose of D-galactose induces changes that resemble natural aging in animals, including shortened life span caused by oxidative stress damage, chronic inflammation, neurodegeneration, decreased immune response, and gene transcriptional changes. ${ }^{57} \mathrm{~A}$ subcutaneous dose of $100 \mathrm{mg} / \mathrm{kg}$ D-galactose accelerates senescence in mice. ${ }^{5}$ This is equivalent to $6-10 \mathrm{~g}$ in humans, corresponding to 1-2 glasses of milk. Based on a concentration of lactose in cow's milk of approximately $5 \%$, one glass of milk comprises about $5 \mathrm{~g}$ of $\mathrm{D}$-galactose. The increase of oxidative stress with aging and chronic low grade inflammation is not 
only a pathogenetic mechanism of cardiovascular disease and cancer in humans ${ }^{89}$ but also a mechanism of age related bone loss and sarcopenia. ${ }^{9}{ }^{10}$ The high amount of lactose and therefore D-galactose in milk with theoretical influences on processes such as oxidative stress and inflammation makes the recommendations to increase milk intake for prevention of fractures a conceivable contradiction.

Because of the high content of lactose in milk, we hypothesised that high consumption of milk may increase oxidative stress, which in turn affects the risk of mortality and fracture. Meta-analyses of cohort studies for the association between dairy and milk intake in relation to mortality ${ }^{11}$ and fractures ${ }^{12} 13$ have displayed no clear pattern of risk, and evidence from randomised trials are lacking. Separating milk intake from the consumption of other dairy products may be of importance since a less pronounced induction of oxidative stress and inflammation in humans is expected with cheese and fermented dairy products (for example, soured milk and yogurt) because of their lower or non-existent lactose and galactose content, ${ }^{14}{ }^{15}$ possible probiotic antioxidant and anti-inflammatory effects, ${ }^{16-18}$ and effects on gut microbiota. ${ }^{19-21}$ Indeed, a high intake of fermented milk products has been associated with a decreased risk of cardiovascular diseases, ${ }^{18}{ }^{22-24}$ whereas a high milk intake is related to a tendency of an unfavourable risk profile for the development of diabetes and cardiovascular disease. ${ }^{18}{ }^{2324} \mathrm{We}$ therefore assessed the relation between high milk intake with risk of death and fractures in women and men. We also studied biological markers of oxidative stress and inflammation in relation to milk intake in humans.

\section{Methods}

We used two community based cohorts, the Swedish Mammography Cohort ${ }^{25} 26$ and the Cohort of Swedish Men, ${ }^{27}$ to analyse the association of milk consumption and mortality and fracture rates. Figure $1 \Downarrow$ shows the study sample. In 1987-90, all 90303 women aged 39-74 years residing in two Swedish counties (Uppsala and Västmanland, both in central Sweden) received a postal invitation to a routine mammography screening. Enclosed with this invitation was a questionnaire covering both diet (food frequency questionnaire) and lifestyle, which was completed by $74 \%$ of the women. In 1997, a subsequent, expanded questionnaire was sent to those who were still living in the study area (response rate $70 \%$ ). In the present study 61433 women in the Swedish Mammography Cohort with baseline data from 1987-90 and 38984 with updated information from 1997 were available for analysis.

The Cohort of Swedish Men was created in the autumn of 1997. All men, aged 45-79 years, residing in Örebro and Västmanland counties in central Sweden were invited to participate in the study ( $n=100303)$. Enclosed with this invitation was a questionnaire covering both diet (food frequency questionnaire) and lifestyle, which was completed by 48850 men. Despite the response rate of $49 \%$, the Cohort of Swedish Men is considered representative of Swedish men in this age range in terms of age distribution, educational level, and prevalence of being overweight. ${ }^{27}$ After exclusions, the final sample included 45 339 men (fig 1).

\section{Food frequency questionnaires}

The participants reported their average frequency of consumption of up to 96 foods and beverages during the past year, ${ }^{25} 28$ - that is, how many servings, a day or a week, they consumed of common foods, including milk, fermented milk, yogurt, and cheese. Instructions were given that one serving of milk corresponded to one glass of $200 \mathrm{~mL}$. In the first questionnaire in the Swedish Mammography Cohort the categories were prespecified, but in the second questionnaire and the one used in the Cohort of Swedish Men, participants could fill in the exact number of servings of the dairy products (milk, fermented milk, yogurt, and cheese) they consumed a day or a week. Milk intake was specified according to fat content, and we summed intake into a single measure representing total milk intake on a continuous scale. We estimated nutrient intakes by multiplying the consumption frequency of each food item by the nutrient content of age specific portion sizes and reference data obtained from the Swedish National Food Agency database. ${ }^{29}$ The residual method was used to adjust all nutrient intakes for total energy intake. ${ }^{30}$ According to validation studies of milk intake, the correlation between the food frequency questionnaire and four, seven day food records every third month, a gold standard reference, has been approximately $0.7 .{ }^{31}$ Furthermore, in both sexes we have found a positive association between reported intake of milk and the fat tissue content of pentadecanoic acid, a biological marker reflecting average long term intake of milk fat- that is, present in both milk and fermented milk products. ${ }^{32}{ }^{33}$

\section{Outcomes}

We considered outcomes registered between study entry (date of mammography screening in 1987-90 for the Swedish Mammography Cohort and 1 January 1998 for the Cohort of Swedish Men) and 31 December 2010. Follow-up until death was through the Swedish cause of death registry. Complete linkage with the register is possible by the personal identity number provided to all Swedish residents. We used the underlying cause of death from the Swedish cause of death registry to define mortality from all causes, cardiovascular diseases (international classification of diseases, 10th revision; ICD-10 codes I00-I99), and cancer (ICD-10 C-codes). For 1987 to 1996 , we used corresponding ICD-9 codes. Accuracy of classification of causes of death in the Swedish registry is high. ${ }^{34}$ We collated fracture events through linkage with the Swedish national patient registry. We defined any fracture event as a hospital admission or an outpatient visit with ICD-10 codes S12-S92. Hip fracture cases were defined by the codes S720-S722. Using a previously validated and accurate method, we separated admissions for incident fracture from readmissions for a previous fracture event. ${ }^{25}{ }^{35}$ In analyses we used only the first fracture event. We retained cases of fractures due to suspected high impact trauma in the analysis since there are indications of comparable increases in the risks of low impact and high impact trauma fractures in association with decreasing bone density in elderly people ( $\geq 60$ years). ${ }^{36}{ }^{37}$ Pathologic fractures as a consequence of a tumour were not included as an outcome.

\section{Comorbidity and other additional information}

From the questionnaires we obtained information on lifestyle, weight, and height. For the Swedish Mammography Cohort the questionnaires also covered information on use of postmenopausal oestrogen therapy, menopausal status, and parity. In the 1997 questionnaires for both cohorts, information was collected on smoking status, ever use of cortisone, and leisure time physical activity during the past year, with five predefined categories ranging from one hour a week to more than five hours a week. This physical activity assessment is valid compared with activity records and accelerometer data. ${ }^{38}$ We divided educational level into four categories: $<9$ years, $10-12$ years, $>12$ years, and other (such as vocational). Living 
alone was categorised based on marital status (yes: unmarried, divorced, widow/widower; no: married, cohabiting). To calculate Charlson's comorbidity index we collated diagnosis codes from the national patient registry. ${ }^{39}$

\section{Biomarkers}

D-galactose supplementation in animals has been shown to increase oxidative stress and inflammation..$^{4-7}$ To assess the association between milk intake and biological markers of oxidative stress and inflammation (fig 1), we additionally analysed a clinical subcohort of the Swedish Mammography Cohor ${ }^{25}$ and the previously described Uppsala Longitudinal Study of Adult Men cohort. ${ }^{41}$ We assessed food intake by a third food frequency questionnaire in the Swedish Mammography Cohort Clinical ( $\mathrm{n}=5022$; mean age 70 years) and by recording diet for one week at age 71 years in the Uppsala Longitudinal Study of Adult Men ( $\mathrm{n}=1138)$. In 892 women (mean age 70 years) and 633 men (urine collected at age 77 ) we analysed the urine oxidative stress marker 8-iso-PGF2 $\alpha$, a dominant $\mathrm{F}_{2}$-isoprostane and an ideal standard biomarker of oxidative stress in vivo. ${ }^{42}$ We used serum from the same age group in the Uppsala Longitudinal Study of Adult Men to analyse interleukin 6 (a main inflammatory biomarker, $\mathrm{n}=700$ ).

\section{Statistical analysis}

For each participant we calculated time at risk until date of each outcome, date of emigration, or the end of the study period (31 December 2010), whichever occurred first. We used Cox proportional hazards regression for estimation of age adjusted and multivariable adjusted hazard ratios and their $95 \%$ confidence intervals for prespecified categories of milk intake ( $<200,200-399,400-599$, and $\geq 600 \mathrm{~g} / \mathrm{d}$ ) and for continuous milk intake for each $200 \mathrm{~g} / \mathrm{d}$, corresponding to one glass of milk. Because other dairy products may have different health effects from that of milk, ${ }^{183}$ we additionally studied intake of fermented milk and cheese as exposures. The proportional hazard assumptions were confirmed graphically by log-log plots. We assessed non-linear trends of risk using restricted cubic-spline Cox regression with three knots placed at centiles 10,50 , and 90 of the milk product intake. ${ }^{43}$

We used the directed acyclic graph approach ${ }^{44}$ to select suitable covariates for the multivariable model (see supplementary appendix figure A). The model included age, total energy intake, body mass index, height (all continuous), educational level ( $\leq 9$, 10-12, >12 years, other), living alone (yes/no), calcium supplementation (yes/no), vitamin D supplementation (yes/no), ever use of cortisone (yes/no), a healthy dietary pattern, as previously described ${ }^{45}$ (continuous), physical activity (five categories), smoking status (never, former, current), and the Charlson comorbidity index (continuous, 1-16). We included other potential covariates such as menopausal status; hormone replacement therapy; intakes of calcium, vitamin $\mathrm{D}$, total fat, saturated fat, retinol, alcohol, potassium, phosphorus, and protein; parity; and previous fracture of any type (the last when analysing hip fracture as an outcome, in a second multivariable model to assess whether these covariates confounded or mediated potential associations). In the Swedish Mammography Cohort, of which we had access to information from repeat questionnaires, we time updated exposures and covariates, theoretically yielding stronger outcome associations. ${ }^{46}$ The analysis in the Cohort of Swedish Men was based on a single exposure assessment. Using the Markov chain Monte Carlo multiple imputation methods, we imputed covariates not assessed in the baseline questionnaire of the Swedish Mammography Cohort in 1987-90 but assessed in the second questionnaire in 1997 (for example, smoking status and physical activity). We performed sensitivity analysis limiting the analysis to baseline data at 1987-90 and 1997 using ordinary Cox's regression without time updated information. In an additional sensitivity analysis, we adjusted our estimates for milk intake by fermented milk and cheese intakes, and vice versa. We also adjusted our second multivariable model for additional nutrients (except lactose) known to be constituents of milk. Accordingly, we therefore evaluated the change of our hazard ratios after adjustment for intakes of riboflavin, thiamine, niacin, vitamin B6, vitamin B12, folate, $\beta$ carotene, iron, magnesium, sodium, selenium, and zinc.

To assess the influence of competing events, we compared cumulative incidence curves for hip fracture, treating death from all causes as competing event, with the Kaplan-Meier curves for hip fracture by categories of milk intake. ${ }^{47}$ Even though competing risk analysis is not considered appropriate for causal analysis, which was the purpose of our study, it can provide additional valuable information for risk prediction. ${ }^{48} \mathrm{We}$ undertook a further sensitivity analysis with any type of vehicle related non-fracture incident as an outcome (identified by ICD-10 codes V01-99 excluding simultaneous fracture), which should theoretically be unrelated to consumption of milk. We evaluated whether a history of fracture was associated with milk consumption in the Uppsala Longitudinal Study of Adult Men cohort and whether experiencing a fracture or comorbidity between the first and second food frequency questionnaires was associated with changed milk consumption in the Swedish Mammography Cohort.

Finally, we used cubic-spline regression analysis to assess the relation between intake of milk, fermented milk, or yogurt, cheese, the urine oxidative stress marker 8-iso-PGF2 $\alpha$, and serum interleukin 6 . Before analysis we log transformed both biomarkers because of their skewed distributions. We adjusted the estimates for age, body mass index, energy intake, education (four categories), smoking status (never, former, current), and physical activity (four categories). The statistical analyses were performed with STATA 11.2 (StataCorp, College Station, TX) and SAS, version 9.3 (SAS Institute, Cary, NC).

\section{Results}

Table $1 \Downarrow$ lists the characteristics of the study participants by categories of milk intake. Mean intake of milk at baseline in the Swedish Mammography Cohort was $240 \mathrm{~g}$ a day and in the Cohort of Swedish Men was $290 \mathrm{~g}$ a day. With increasing categories of milk intake the reported intake for most other nutrients, including energy intake, also increased, although alcohol intake tended to decrease. There were generally small differences between categories of milk intake in body stature, nutritional supplement use, marital status, comorbidity, educational level, smoking status, and physical activity level.

During a median of 22 years of follow-up and 1231818 person years at risk in the Swedish Mammography Cohort, 15541 women died. The underlying cause of death was cardiovascular disease in 5278 women and cancer in 3283 women. We ascertained that 17252 women had any type of fracture, of whom 4259 had had a hip fracture. During a median of 13 years of follow-up and 534094 person years at risk within the Cohort of Swedish Men, 10112 men died (4568 from cardiovascular causes and 2881 from cancer) and 5379 had any type of fracture; of these, 1166 men had a hip fracture.

Among women in the Swedish Mammography Cohort, with analysis based on repeated exposure measurements, we observed a positive association between milk intake and total mortality 
as well as fracture, especially hip fracture (table $2 \Downarrow$ and adjusted spline curves in fig $2 \Downarrow$ ). In women, higher rates were observed for death from all causes (adjusted hazard ratio 1.15, 95\% confidence interval 1.13 to 1.17 , for each glass of milk), cardiovascular disease $(1.15,1.12$ to 1.19 , for each glass of milk), and cancer (1.07, 1.02 to 1.11 , for each glass of milk) (table 2 and fig $3 \Downarrow$ ). Milk consumption corresponding to three or more glasses of milk a day (mean $680 \mathrm{~g}$ a day) compared with less than one glass a day (mean $60 \mathrm{~g}$ a day), was associated with a hazard ratio of total mortality of 1.93 (1.80 to 2.06) in women, with approximately similar estimates for cardiovascular mortality and somewhat lower for cancer mortality $(1.44,1.23$ to 1.69). For women who consumed three or more glasses of milk a day the hazard ratio for any fracture was 1.16 (1.08 to 1.25 ) and for hip fracture was 1.60 (1.39 to 1.84 ).

In an analysis based on a single exposure assessment, men in the Cohort of Swedish Men also had a higher rate of death with higher milk consumption (table 2, fig 2). However, the excess risk was less pronounced than in women, with an adjusted hazard ratio of 1.10 (95\% confidence interval 1.03 to 1.17 ) for three or more glasses of milk a day (mean $830 \mathrm{~g}$ a day) compared with less than one glass a day (mean $50 \mathrm{~g}$ a day) and was mainly associated with an increased rate of cardiovascular death (table 2 and fig 3). No reduction in all fractures or hip fracture rates with increasing milk intake was observed in men (fig 2).

\section{Other dairy products}

Tables A and B in the supplementary appendix show the baseline characteristics of the participants by categories of cheese and fermented milk products (yogurt and other soured milk products). The distribution of the covariates displayed a similar pattern to that of milk intake categories. In a sensitivity analysis, the risk estimates of the outcomes associated with consumption of cheese or fermented milk products were in the opposite direction of estimates associated with milk consumption. Thus women with a high intake of cheese or fermented milk products compared with women with low intakes had lower mortality and fracture rates (see supplementary tables C and D). For each serving the rate of mortality and hip fractures was reduced by $10-15 \%(\mathrm{P}<0.001)$. Risk reductions in men, based on a single exposure assessment, were more modest or were non-existent (see supplementary tables $\mathrm{C}$ and $\mathrm{D}$ ).

\section{Sensitivity analysis}

We performed an extended multivariable model to evaluate whether nutrients known to be associated with osteoporosis or fracture risk (calcium, vitamin D, phosphorus, fat, protein, and retinol) influenced our estimates. Adjustment for these nutrients further strengthened the association between milk intake and outcomes (see supplementary table E). The associations remained robust after performing further sensitivity analysis. Accordingly, our estimates for milk intake were independent of consumption by fermented milk and cheese (see supplementary tables F and G). The estimates of fermented milk and cheese were attenuated when adjusted for milk intake and each other (see supplementary tables F and G). We further extended our second multivariable model to evaluate the influence on our estimates by adjustment for additional nutrients known to be constituents of milk, but the hazard ratios were only changed by $4 \%$ or less.

To investigate possible bias in the Swedish Mammography Cohort introduced by using time updated information in the models we conducted additional sensitivity analyses. Firstly, we included only baseline data, without updating with information from the second questionnaire (see supplementary table $\mathrm{H}$ ). Secondly, we used the second questionnaire as baseline (see supplementary table I). These analyses indicated a higher risk of death and fracture with high milk intakes, although with attenuated estimates compared with time updated intakes (table 2).

The reporting of milk consumption did not seem to be influenced by comorbid conditions (see supplementary table J). Thus women in the Swedish Mammography Cohort who had experienced one comorbidity or two comorbidities or more in the follow-up time between the first and the second food frequency questionnaire had a change in milk consumption similar to those who did not experience comorbidities during the period. Similarly, women who had a fracture before the second food frequency questionnaire did not increase their milk consumption. The reporting of fermented milk products was not affected by comorbidity status (see supplementary table $\mathrm{J}$ ). No difference $(\mathrm{P}=0.31)$ in milk consumption was noted between the $13 \%$ of Uppsala Longitudinal Study of Adult Men who reported that at least one parent had had a hip fracture (1.2 glasses of milk/d, 95\% confidence interval 1.0 to 1.3 ) and those who did not have a family history of hip fracture (1.3 glass of milk/d, 1.2 to 1.3). We did not find an impact of competing events from mortality for the association between milk intake and hip fracture (see supplementary figure B). The incidence of vehicle related non-fracture incidents as a consequence ( $\mathrm{n}=1161$ women) was not higher among those with a high milk consumption (hazard ratio $0.96,95 \%$ confidence interval 0.90 to 1.03 for each glass of milk). Finally, the excess rate of mortality associated with higher milk consumption was also evident in both sexes without a fracture during follow-up (data not shown).

\section{Milk intake, oxidative stress, and inflammation}

We further investigated whether milk intake was associated with oxidative stress and inflammation. Milk intake was positively associated with 8 -iso-PGF2 $\alpha$ in both sexes, and with interleukin 6 in men (fig $4 \Downarrow$ ). Consumption of fermented milk products (soured milk and yogurt) indicated a negative relation with both the oxidative stress and the inflammatory markers (see supplementary figure C, panel A). No such association was observed with cheese intake (see supplementary figure C, panel B).

\section{Discussion}

We observed a dose dependent higher rate of both mortality and fracture in women and a higher rate of mortality in men with milk intake, a pattern not discerned with other dairy products. Milk intake was not associated with fracture rate in men. There were positive associations between milk intake and concentrations of markers for oxidative stress and inflammation.

\section{Strengths and weaknesses of this study}

Our study strengths include the population based prospective designs in both sexes in a setting with a large range of milk intake. Using repeat measurements of dietary intake in the Swedish Mammography Cohort increased the accuracy and precision of measurements on dietary intake. We traced outcomes through national healthcare registers and deterministic record linkage, permitting complete ascertainment. Also, we adjusted for several important covariates, although residual confounding cannot be excluded-for example, even though the results were adjusted for some aspects of socioeconomic 
status (education and marital status), additional nuances may not have been adequately captured by our observational study design. The findings were independent of non-lactose nutrients in milk. However, we did not consider the non-nutritional contents of dairy products such as persistent organic pollutants ${ }^{49}$ and heavy metals, ${ }^{50}$ but these contaminants should be concentrated not only in milk but also in fermented milk products, which we found to be associated with reduced rates of mortality and fracture.

Our results might not apply to people of other ethnic origins, such as those with a high prevalence of lactose intolerance, or to children and adolescents. Nutrient concentrations in milk and other dairy products are variable and depend on factors such as food fortification, biosynthesis, the animal's diet, and physicochemical conditions, ${ }^{51}$ which might affect the generalisability of our results. Theoretically, the findings on fractures might be explained by a reverse causation phenomenon, where people with a higher predisposition for osteoporosis may have deliberately increased their milk intake. We investigated time to first fracture, which reduces the likelihood of biased estimates. Furthermore, high milk consumption was also related to higher mortality among those without a fracture during follow-up. In the analyses we did not consider fractures caused by metastatic cancer, but cases of fractures due to suspected high impact trauma were, as recommended, ${ }^{36}$ retained in the analysis since these fractures are-as ordinary fragility fractures-also more common in those with low bone mineral density. The possibility of a reverse causation theory is also contradicted by the fact that fermented dairy products were related to a reduced risk of fracture and that a personal or a family history of hip fracture was not associated with a higher milk intake. Additionally, the change in average reported consumption of milk in the Swedish Mammography Cohort during a long follow-up was not affected by change in comorbidity status. Furthermore, prospective designs are more likely to generate non-differential misclassification and thus attenuate the evaluated association. None the less, we cannot rule out the possibility that our design or analysis failed to capture a reverse causation phenomenon.

\section{Comparison with other studies}

A high intake of milk is accompanied by a higher energy intake, as indicated by the baseline characteristics of our participants. However, results from both cohort studies ${ }^{52}{ }^{53}$ and randomised controlled trials ${ }^{545}$ show that a high intake of dairy products is not associated with an increase in weight or body mass index despite a higher intake of energy. These results are in line with the present study where those who reported a high milk intake also had higher energy intake but a similar body mass index compared with women and men with a lower milk intake.

Ecological studies suggest higher mortality rates from fracture and ischaemic heart disease in countries with high milk consumption. ${ }^{567}$ Higher milk consumption has also been suggested to affect the risk of certain cancers and cardiovascular disease. ${ }^{115859}$ Meta-analyses of cohort studies on the association between milk intake and mortality ${ }^{11}$ and fracture ${ }^{12}{ }^{13}$ have shown significant heterogeneity between studies. In the higher milk consumption category, for example, some show lower mortality rates and some show higher. Comparisons between studies are hampered by differences in exposure range, the pooling of different milk products as exposure, the method used for dietary assessment, the general dietary pattern, the prevalence of lactose intolerance, outcome assessment, and study size. To consider the totality of evidence concerning the role of milk consumption in death and fractures, we recommend that these differences between study designs are considered in future metaregression analyses of observational studies. Our present investigation should not be evaluated in isolation and its merits should be judged in light of other study findings. The fact that no randomised trial has examined the effect of milk intake on incidence of mortality and fractures, long term experimental evidence is needed to confirm a causal association between higher milk intake and higher mortality. Another possible analytical approach might be the use of genetic variation in lactase persistence using a Mendelian randomisation study design, but these specific genetic variants are probably weak as an instrumental variable.$^{60}$ In addition, the dose-response relation with milk intake is not readily observed with such a design and neither is the consideration of type of dairy product consumed. Previous studies also conclude that gene-environmental interaction seems to be of importance for this specific gene expression, and pleiotropic effects cannot be excluded. ${ }^{61}{ }^{62}$

Our present study of two cohorts included a larger number of outcomes than the total number of events included in the meta-analyses of previous studies. ${ }^{11} 13$ To counteract the random misclassification occurring in cohort studies and leading to conservatively biased risk estimates, studies with a large number of outcomes are needed and also preferentially repeat dietary assessments to reduce misclassification of the exposure. Indeed, we found a stronger association with milk intake and both mortality and fractures in women than in men. This inequality might be explained by real sex differences but also by the larger size of the female cohort study and by the repeat food frequency questionnaire surveys and time updated analysis. It should be emphasised that when a single exposure assessment was applied in the sensitivity analysis of the Swedish Mammography Cohort, by use of either the first or the second food frequency questionnaire, the hazard ratios were attenuated compared with the time dependent exposure analysis and were also similar to the estimates obtained in the male cohort. Therefore, improved validity and precision of the exposure is a likely explanation for the higher risk observed in women.

\section{Comparing milk with other dairy products}

Particularly noteworthy is that intake of fermented milk products such as yogurt and soured milk and cheese were associated with lower rates of fracture and mortality. Furthermore, we observed a positive association only between milk intake and markers of oxidative stress (urine 8-iso-PGF2 $\alpha$ ) and inflammation (serum interleukin 6). Previously, we found a negative relation between bone mineral density and 8 -iso-PGF $2 \alpha{ }^{42}{ }^{63}$ Interleukin 6 seems to be causally related to cardiovascular disease ${ }^{64}$ and may influence bone loss and osteoporosis. ${ }^{65}$ Importantly, those who consume high amounts of non-fermented milk have a more non-favourable cardiovascular risk factor profile, with higher blood pressure, lower high density lipoprotein cholesterol levels, and higher insulin resistance. ${ }^{18}$ In contrast, intake of cheese and fermented milk products is related to higher high density lipoprotein cholesterol levels, less insulin resistance, and a lower risk of myocardial infarction. ${ }^{182-24}$ In addition, a recent small randomised cross over study indicated that the intake of a fermented dairy diet seemed to provide a more favourable biomarker profile than that of a non-fermented dairy diet. ${ }^{66}$

\section{Potential mechanism}

One potential candidate for the discrepant results for different types of dairy products is D-galactose content. The intake of $\mathrm{D}$-galactose from non-fermented milk is considerably higher than that from other food sources, including cheese and fermented milk products. Non-dairy sources of D-galactose are 
mainly cereals, vegetables, and fruits, ${ }^{67}$ but the concentration of galactose and the amount ingested from these sources accounts for a small proportion of the total intake of galactose. Put into perspective, the amount of lactose in one glass of milk corresponds to approximately $5 \mathrm{~g}$ of galactose, whereas the amount in $100 \mathrm{~g}$ of fruits or vegetables ${ }^{67}$ is measured in milligrams or tens of milligrams. D-galactose given to laboratory animals (mice, rats, and drosophila flies) is an established experimental model for premature aging, including shortened life span caused by oxidative stress and chronic inflammation, ${ }^{4-7}$ but whether this mechanism can be generalised to humans needs further scientific support. However, galactosaemia is a genetic disorder that results from loss of

galactose-1P-uridylyltransferase, with accumulation of galactose in blood and other tissues as a consequence. ${ }^{68}{ }^{69}$ Affected infants experience a rapid escalation of potentially lethal acute symptoms after exposure to milk, and experimental models display oxidative stress as a mechanism for the development of disease ${ }^{68}$ Even with dietary restrictions of galactose intake these patients have higher circulating levels of galactose and an increased risk for chronic diseases in adulthood, ${ }^{69}$ including osteoporosis. $^{70}$

\section{Conclusion}

A higher consumption of milk in women and men is not accompanied by a lower risk of fracture and instead may be associated with a higher rate of death. Consequently, there may be a link between the lactose and galactose content of milk and risk as suggested in our hypothesis, although causality needs be tested using experimental study designs. Our results may question the validity of recommendations to consume high amounts of milk to prevent fragility fractures. ${ }^{371} 72$ The results should, however, be interpreted cautiously given the observational design of our study. The findings merit independent replication before they can be used for dietary recommendations.

Contributors: $\mathrm{KM}$ and $\mathrm{LB}$ designed the study and drafted the manuscript. KM and LB analysed the data. LB, HM, SL, SB, EWL, and AW contributed to the interpretation of the data and revision of the manuscript. KM had primary responsibility for final content and acts as guarantor. All authors read and approved the final manuscript. The funders of the study had no role in the study design, data collection, data analysis, data interpretation, writing of the report, or the decision to submit the article for publication.

Funding: This study was supported by grants from the Swedish Research Council. EWL is employed by the Swedish National Food Agency. The views in this article do not necessarily represent those of the agency. Competing interests: All authors have completed the ICMJE uniform disclosure form at www.icmje.org/coi_disclosure.pdf and declare: no support from any organisation for the submitted work; no financial relationships with any organisations that might have an interest in the submitted work in the previous three years; no other relationships or activities that could appear to have influenced the submitted work.

Ethical approval: The Swedish Mammography Cohort, the clinical subcohort of the Swedish Mammography Cohort, and the Cohort of Swedish Men were approved by the regional research ethics board at Karolinska Insitutet. The Uppsala Longitudinal Study of Adult Men was approved by the regional research ethics board at Uppsala University. All participants gave informed consent.

Data sharing: Summary data from the Uppsala Longitudinal Study of Adult Men are available at http://www.pubcare.uu.se/ULSAM.

Transparency: The lead author (KM) affirms that the manuscript is an honest, accurate, and transparent account of the study being reported; that no important aspects of the study have been omitted; and that any discrepancies from the study as planned (and, if relevant, registered) have been explained.

Burger J, Kirchner M, Bramanti B, Haak W, Thomas MG. Absence of the lactase-persistence-associated allele in early Neolithic Europeans. Proc Natl Acad Sci U S A 2007:104:3736-41.

2 Simoons FJ. The geographic hypothesis and lactose malabsorption. A weighing of the evidence. Am J Dig Dis 1978;23:963-80

3 Heaney RP. Dairy and bone health. J Am Coll Nutr 2009;28(Suppl 1):82S-90S.

4 Song X, Bao M, Li D, Li YM. Advanced glycation in D-galactose induced mouse aging model. Mech Ageing Dev 1999;108:239-51.

5 Cui X, Zuo P, Zhang Q, Li X, Hu Y, Long J, et al. Chronic systemic D-galactose exposure induces memory loss, neurodegeneration, and oxidative damage in mice: protective effects of R-alpha-lipoic acid. J Neurosci Res 2006;83:1584-90.

6 Hao L, Huang H, Gao J, Marshall C, Chen Y, Xiao M. The influence of gender, age and treatment time on brain oxidative stress and memory impairment induced by $\mathrm{d}$-galactose in mice. Neurosci Lett 2014;571C:45-9.

7 Cui X, Wang L, Zuo P, Han Z, Fang Z, Li W, et al. D-galactose-caused life shortening in Drosophila melanogaster and Musca domestica is associated with oxidative stress. Biogerontology 2004;5:317-25.

8 Reuter S, Gupta SC, Chaturvedi MM, Aggarwal BB. Oxidative stress, inflammation, and cancer: how are they linked? Free Radic Biol Med 2010;49:1603-16.

9 Manolagas SC, Parfitt AM. What old means to bone. Trends Endocrinol Metab 2010;21:369-74.

10 Michaëlsson K, Wolk A, Byberg L, Ärnlöv J, Melhus H. Intake and serum concentrations of alpha-tocopherol in relation to fractures in elderly women and men: 2 cohort studies. Am J Clin Nutr 2014;99:107-14.

11 Soedamah-Muthu SS, Ding EL, Al-Delaimy WK, Hu FB, Engberink MF, Willett WC, et al. Milk and dairy consumption and incidence of cardiovascular diseases and all-cause mortality: dose-response meta-analysis of prospective cohort studies. Am J Clin Nutr 2011:93:158-71.

12 Kanis JA, Johansson H, Oden A, De Laet C, Johnell O, Eisman JA, et al. A meta-analysis of milk intake and fracture risk: low utility for case finding. Osteoporos Int 2005;16:799-804.

13 Bischoff-Ferrari HA, Dawson-Hughes B, Baron JA, Kanis JA, Orav EJ, Staehelin HB, et al. Milk intake and risk of hip fracture in men and women: a meta-analysis of prospective cohort studies. J Bone Miner Res 2011;26:833-9.

14 Alm L. Effect of fermentation on lactose, glucose, and galactose content in milk and suitability of fermented milk products for lactose intolerant individuals. J Dairy Sci 1982;65:346-52.

15 Portnoi PA, MacDonald A. Determination of the lactose and galactose content of cheese for use in the galactosaemia diet. J Hum Nutr Diet 2009;22:400-8.

16 Kumar M, Kumar A, Nagpal R, Mohania D, Behare P, Verma V, et al. Cancer-preventing attributes of probiotics: an update. Int J Food Sci Nutr 2010;61:473-96.

17 Nestel PJ, Mellett N, Pally S, Wong G, Barlow CK, Croft K, et al. Effects of low-fat or full-fat fermented and non-fermented dairy foods on selected cardiovascular biomarkers in overweight adults. Br J Nutr 2013:110:2242-9.

18 Sonestedt E, Wirfalt E, Wallstrom P, Gullberg B, Orho-Melander M, Hedblad B. Dairy products and its association with incidence of cardiovascular disease: the Malmo diet and cancer cohort. Eur J Epidemiol 2011:26:609-18.

19 Ceapa C, Wopereis H, Rezaiki L, Kleerebezem M, Knol J, Oozeer R. Influence of fermented milk products, prebiotics and probiotics on microbiota composition and health. Best Pract Res Clin Gastroenterol 2013;27:139-55.

20 Sommer F, Backhed F. The gut microbiota - masters of host development and physiology. Nat Rev Microbiol 2013;11:227-38.

21 McNulty NP, Yatsunenko T, Hsiao A, Faith JJ, Muegge BD, Goodman AL, et al. The impact of a consortium of fermented milk strains on the gut microbiome of gnotobiotic mice and monozygotic twins. Sci Transl Med 2011;3:106ra06.

22 Astrup A. Yogurt and dairy product consumption to prevent cardiometabolic diseases: epidemiologic and experimental studies. Am J Clin Nutr 2014;99:1235S-42S.

23 Patterson E, Larsson SC, Wolk A, Akesson A. Association between dairy food consumption and risk of myocardial infarction in women differs by type of dairy food. $J$ Nutr 2013;143:74-9.

24 Huth PJ, Park KM. Influence of dairy product and milk fat consumption on cardiovascular disease risk: a review of the evidence. Adv Nutr 2012;3:266-85.

25 Warensjö E, Byberg L, Melhus H, Gedeborg R, Mallmin H, Wolk A, et al. Dietary calcium intake and risk of fracture and osteoporosis: prospective longitudinal cohort study. BMJ ;342:d1473.

26 Michaëlsson K, Melhus H, Warensjö Lemming E, Wolk A, Byberg L. Long term calcium intake and rates of all cause and cardiovascular mortality: community based prospective longitudinal cohort study. BMJ 2013;346:f228.

27 Thomas LD, Michaelsson K, Julin B, Wolk A, Akesson A. Dietary cadmium exposure and fracture incidence among men: a population-based prospective cohort study. J Bone Miner Res 2011:26:1601-8.

28 Larsson SC, Bergkvist L, Wolk A. Long-term dietary calcium intake and breast cancer risk in a prospective cohort of women. Am J Clin Nutr 2009;89:277-82.

29 Bergström L, Kylberg E, Hagman U, Eriksson H, Bruce Å. The food composition database KOST: the National Food Administration's information system for nutritive values of food [Swedish]. Vår föda 1991;43:439-47.

30 Willett WC, Howe GR, Kushi LH. Adjustment for total energy intake in epidemiologic studies. Am J Clin Nutr 1997:65(4 Suppl):1220S-28S; discussion 29S-31S.

31 Larsson SC, Andersson SO, Johansson JE, Wolk A. Cultured milk, yoghurt, and dairy intake in relation to bladder cancer risk in a prospective study of Swedish women and men. Am J Clin Nutr 2008;88:1083-7.

32 Jiang J, Wolk A, Vessby B. Relation between the intake of milk fat and the occurrence of conjugated linoleic acid in human adipose tissue. Am J Clin Nutr 1999;70:21-7.

33 Wolk A, Vessby B, Ljung H, Barrefors P. Evaluation of a biological marker of dairy fat intake. Am J Clin Nutr 1998;68:291-5.

34 Tunstall-Pedoe H, Kuulasmaa K, Amouyel P, Arveiler D, Rajakangas AM, Pajak A. Myocardial infarction and coronary deaths in the World Health Organization MONICA Project. Registration procedures, event rates, and case-fatality rates in 38 populations from 21 countries in four continents. Circulation 1994;90:583-612. 


\section{What is already known on this topic}

A high milk intake is recommended for the prevention of osteoporotic fractures

Milk is the major dietary source of galactose intake

The addition of galactose by injection or in the diet is an established animal model of aging by induction of oxidative stress and inflammation Results of previous research on the importance of milk intake for the prevention of fractures and the influence on mortality rates are conflicting

\section{What this study adds}

A high milk intake in both sexes is associated with higher mortality and fracture rates and with higher levels of oxidative stress and inflammatory biomarkers

Such a pattern was not observed with high intake of fermented milk products

35 Gedeborg R, Engquist H, Berglund L, Michaelsson K. Identification of incident injuries in hospital discharge registers. Epidemiology 2008;19:860-7.

36 Sanders KM, Pasco JA, Ugoni AM, Nicholson GC, Seeman E, Martin TJ, et al. The exclusion of high trauma fractures may underestimate the prevalence of bone fragility fractures in the community: the Geelong Osteoporosis Study. J Bone Miner Res 1998;13:1337-42.

37 Mackey DC, Lui LY, Cawthon PM, Bauer DC, Nevitt MC, Cauley JA, et al. High-trauma fractures and low bone mineral density in older women and men. JAMA 2007:298:2381-8.

38 Orsini N, Bellocco R, Bottai M, Hagstromer M, Sjostrom M, Pagano M, et al. Validity of self-reported total physical activity questionnaire among older women. Eur J Epidemiol 2008;23:661-7.

39 Charlson ME, Pompei P, Ales KL, MacKenzie CR. A new method of classifying prognostic comorbidity in longitudinal studies: development and validation. $J$ Chronic Dis 1987:40:373-83.

40 Quan H, Sundararajan V, Halfon P, Fong A, Burnand B, Luthi J, et al. Coding algorithms for defining comorbidities in ICD-9-CM and ICD-10 administrative data. Med Care 2005;43:1130-9.

41 Michaëlsson K, Lithell H, Vessby B, Melhus $\mathrm{H}$. Serum retinol levels and the risk of fracture. N Engl J Med 2003;348:287-94

42 Basu S, Michaëlsson K, Olofsson H, Johansson S, Melhus H. Association between oxidative stress and bone mineral density. Biochem Biophys Res Commun 2001;288:275-9.

43 STATA Corporation. Stata reference manual, release 11. In: Stata Corporation, ed. Stata Press, 2009.

44 VanderWeele TJ, Hernan MA, Robins JM. Causal directed acyclic graphs and the direction of unmeasured confounding bias. Epidemiology 2008;19:720-8.

45 Michaëlsson $\mathrm{K}$, Melhus $\mathrm{H}$, Warensjö Lemming E, Wolk A, Byberg L. Long term calcium intake and rates of all cause and cardiovascular mortality: community based prospective longitudinal cohort study. BMJ 2013;346:f228.

46 Hu FB, Stampfer MJ, Rimm E, Ascherio A, Rosner BA, Spiegelman D, et al. Dietary fat and coronary heart disease: a comparison of approaches for adjusting for total energy intake and modeling repeated dietary measurements. Am J Epidemiol 1999;149:531-40.

47 Lin DY. Non-parametric inference for cumulative incidence functions in competing risks studies. Stat Med 1997;16:901-10.

48 Lau B, Cole SR, Gange SJ. Competing risk regression models for epidemiologic data. Am J Epidemiol 2009;170:244-56.

49 Tornkvist A, Glynn A, Aune M, Darnerud PO, Ankarberg EH. PCDD/F, PCB, PBDE, HBCD and chlorinated pesticides in a Swedish market basket from 2005-levels and dietary intake estimations. Chemosphere 2011;83:193-9.

50 Tahvonen R, Kumpulainen J. Lead and cadmium contents in milk, cheese and eggs on the Finnish market. Food Addit Contam 1995;12:789-98

51 Gaucheron F. Milk and dairy products: a unique micronutrient combination. J Am Coll Nutr 2011;30(5 Suppl 1):400S-9S.

52 Louie JC, Flood VM, Hector DJ, Rangan AM, Gill TP. Dairy consumption and overweight and obesity: a systematic review of prospective cohort studies. Obes Rev 2011:12:e582-92.

53 Mozaffarian D, Hao T, Rimm EB, Willett WC, Hu FB. Changes in diet and lifestyle and long-term weight gain in women and men. N Engl J Med 2011;364:2392-404.

54 Abargouei AS, Janghorbani M, Salehi-Marzijarani M, Esmaillzadeh A. Effect of dairy consumption on weight and body composition in adults: a systematic review and meta-analysis of randomized controlled clinical trials. Int J Obes (Lond) 2012;36:1485-93.

55 Chen M, Pan A, Malik VS, Hu FB. Effects of dairy intake on body weight and fat: a meta-analysis of randomized controlled trials. Am J Clin Nutr 2012;96:735-47.
56 Hegsted DM. Fractures, calcium, and the modern diet. Am J Clin Nutr 2001;74:571-3.

57 Segall JJ. Hypothesis: is lactose a dietary risk factor for ischaemic heart disease? Int $J$ Epidemiol 2008:37:1204-8.

58 Song $\mathrm{Y}$, Chavarro JE, Cao Y, Qiu W, Mucci L, Sesso HD, et al. Whole milk intake is associated with prostate cancer-specific mortality among U.S. male physicians. J Nutr 2013;143:189-96.

59 Lampe JW. Dairy products and cancer. J Am Coll Nutr 2011;30(5 Suppl 1):464S-70S.

60 Timpson NJ, Brennan P, Gaborieau V, Moore L, Zaridze D, Matveev V, et al. Can lactase persistence genotype be used to reassess the relationship between renal cell carcinoma and milk drinking? Potentials and problems in the application of Mendelian randomization. Cancer Epidemiol Biomarkers Prev 2010;19:1341-8.

61 Corella D, Arregui M, Coltell O, Portoles O, Guillem-Saiz P, Carrasco P, et al. Association of the LCT-13910C > T polymorphism with obesity and its modulation by dairy products in a Mediterranean population. Obesity (Silver Spring) 2011;19:1707-14

62 Wagh K, Bhatia A, Alexe G, Reddy A, Ravikumar V, Seiler M, et al. Lactase persistence and lipid pathway selection in the Maasai. PLoS One 2012;7:e44751.

63 Östman B, Michaëlsson K, Helmersson J, Byberg L, Gedeborg R, Melhus H, et al. Oxidative stress and bone mineral density in elderly men: antioxidant activity of alpha-tocopherol. Free Radic Biol Med 2009;47:668-73.

64 IL6R Genetics Consortium Emerging Risk Factors Collaboration, Sarwar N, Butterworth AS, Freitag DF, Gregson J, Willeit P, et al. Interleukin-6 receptor pathways in coronary heart disease: a collaborative meta-analysis of 82 studies. Lancet 2012;379:1205-13.

65 Clowes JA, Riggs BL, Khosla S. The role of the immune system in the pathophysiology of osteoporosis. Immunol Rev 2005;208:207-27.

66 Nestel PJ, Mellett N, Pally S, Wong G, Barlow CK, Croft K, et al. Effects of low-fat or full-fat fermented and non-fermented dairy foods on selected cardiovascular biomarkers in overweight adults. Br J Nutr 2013;110:2242-9.

67 Gross KC, Acosta PB. Fruits and vegetables are a source of galactose: implications in planning the diets of patients with galactosaemia. J Inherit Metab Dis 1991;14:253-8.

68 Jumbo-Lucioni PP, Hopson ML, Hang D, Liang Y, Jones DP, Fridovich-Keil JL. Oxidative stress contributes to outcome severity in a Drosophila melanogaster model of classic galactosemia. Dis Models Mech 2013;6:84-94.

69 Lai K, Elsas LJ, Wierenga KJ. Galactose toxicity in animals. IUBMB life 2009;61:1063-74.

70 Batey LA, Welt CK, Rohr F, Wessel A, Anastasoaie V, Feldman HA, et al. Skeletal health in adult patients with classic galactosemia. Osteoporos Int 2013;24:501-9.

71 US Department of Agriculture and US Department of Health and Human Services. Dietary Guidelines for Americans. 2010. www.cnpp.usda.gov/dietaryguidelines.htm.

72 Weaver CM. How sound is the science behind the dietary recommendations for dairy? Am J Clin Nutr 2014;99:1217S-22S.

Accepted: 22 September 2014

\section{Cite this as: BMJ 2014;349:g6015}

This is an Open Access article distributed in accordance with the Creative Commons Attribution Non Commercial (CC BY-NC 3.0) license, which permits others to distribute, remix, adapt, build upon this work non-commercially, and license their derivative works on different terms, provided the original work is properly cited and the use is non-commercial. See: http://creativecommons.org/licenses/by-nc/3.0/. 


\section{Tables}

Table 1| Baseline characteristics of women in Swedish Mammography Cohort (1987-90) and men in Cohort of Swedish Men (1997) by categories of milk intake. Values are numbers (percentages) unless stated otherwise

Categories of daily milk intake

Characteristics

$<1$ glass $(<200 \mathrm{~g} / \mathrm{d}) \quad 1-2$ glasses $(200-399 \mathrm{~g} / \mathrm{d}) \quad 2-3$ glasses $(400-599 \mathrm{~g} / \mathrm{d}) \geq 3$ glasses $(\geq 600 \mathrm{~g} / \mathrm{d})$

Swedish Mammography Cohort

\begin{tabular}{|c|c|c|c|c|}
\hline No & 16926 & 23438 & 15461 & 5608 \\
\hline Mean (SD) age at entry (years) & $53.2(9.6)$ & $54.0(9.7)$ & $54.1(9.9)$ & $52.8(9.6)$ \\
\hline Mean (SD) body mass index $\left(\mathrm{kg} / \mathrm{m}^{2}\right)$ & $24.5(3.8)$ & $24.7(3.8)$ & $25.0(3.9)$ & $24.9(4.1)$ \\
\hline Mean (SD) height $(\mathrm{cm})$ & $164.0(5.7)$ & $164.0(5.7)$ & $164.0(5.8)$ & $164.3(5.9)$ \\
\hline \multicolumn{5}{|l|}{ Mean (SD) nutrient intake: } \\
\hline Energy (kcal/d) & $1412(433)$ & $1535(414)$ & $1707(435)$ & $1965(527)$ \\
\hline Calcium (mg/d) & $733(159)$ & $859(140)$ & $973(144)$ & $1101(175)$ \\
\hline Phosphorus (mg/d) & $1241(185)$ & $1365(165)$ & $1478(175)$ & $1587(204)$ \\
\hline Vitamin D (mg/d) & $3.9(1.7)$ & $4.4(1.2)$ & $4.8(1.4)$ & $5.1(1.7)$ \\
\hline Retinol (mg/d) & $0.94(0.70)$ & $1.03(0.64)$ & $1.09(0.61)$ & $1.09(0.59)$ \\
\hline Protein $(\mathrm{g} / \mathrm{d})$ & $62.2(9.2)$ & $66.4(8.0)$ & $69.9(8.2)$ & $73.1(8.8)$ \\
\hline Total fat $(\mathrm{g} / \mathrm{d})$ & $44.3(17.1)$ & $48.9(16.7)$ & $55.0(18.5)$ & $64.9(24.3)$ \\
\hline Saturated fat $(g / d)$ & $19.0(8.1)$ & $21.4(8.0)$ & $24.5(9.1)$ & $30.0(12.6)$ \\
\hline Alcohol (g/d) & $3.1(3.9)$ & $2.6(3.5)$ & $2.1(3.0)$ & $1.9(3.0)$ \\
\hline Mean (SD) metabolic equivalents (kcal/kg and hour) & $42.2(4.8)$ & $42.4(4.8)$ & $42.6(4.8)$ & $42.8(5.0)$ \\
\hline Calcium supplement use ${ }^{*}$ & $6287(37.1)$ & $7558(32.2)$ & $3976(25.7)$ & $1300(23.2)$ \\
\hline Vitamin D supplement use* & $2539(15.0)$ & $3397(14.5)$ & $1950(12.6)$ & $714(12.7)$ \\
\hline Ever oestrogen replacement use* & $3502(20.7)$ & $5066(21.6)$ & $3518(22.8)$ & $1464(26.1)$ \\
\hline \multicolumn{5}{|l|}{ Education level: } \\
\hline$\leq 9$ years & $13284(78.5)$ & $18721(79.9)$ & $12540(81.1)$ & $4417(78.8)$ \\
\hline 10-12 years & $1370(8.1)$ & $1702(7.3)$ & $1057(6.8)$ & $406(7.2)$ \\
\hline$>12$ years & $897(5.3)$ & $1148(4.9)$ & $632(4.1)$ & $266(4.7)$ \\
\hline other & $1375(8.1)$ & $1867(8.0)$ & $1232(8.0)$ & $519(9.2)$ \\
\hline \multicolumn{5}{|l|}{ Charlson comorbidity: } \\
\hline 0 & $15197(89.8)$ & $21154(90.3)$ & $13 \cdot 866(89.7)$ & $4928(87.9)$ \\
\hline 1 & $1404(8.3)$ & $1798(7.7)$ & $1236(8.0)$ & $533(9.5)$ \\
\hline$\geq 2$ & $325(1.9)$ & $486(2.1)$ & $359(2.3)$ & $147(2.6)$ \\
\hline Nulliparous & $2034(12.0)$ & $2542(10.8)$ & $1556(10.1)$ & $566(10.9)$ \\
\hline Ever cortisone use* & $914(5.4)$ & $1096(4.6)$ & $759(4.9)$ & $262(4.7)$ \\
\hline \multicolumn{5}{|l|}{ Smoker status:* } \\
\hline Current & $3353(19.8)$ & $4295(18.3)$ & $3096(20.0)$ & $1346(24.0)$ \\
\hline Former & $5340(31.6)$ & $6890(29.4)$ & $4459(28.8)$ & $1656(29.5)$ \\
\hline Never & $8233(48.6)$ & $12253(52.3)$ & $7906(51.1)$ & $2606(46.5)$ \\
\hline Living alone & $3958(23.4)$ & $5308(22.6)$ & $3761(24.3)$ & $1441(25.7)$ \\
\hline \multicolumn{5}{|l|}{ Cohort of Swedish Men } \\
\hline No & 18459 & 10841 & 8927 & 7112 \\
\hline Mean (SD) age at entry (years) & $58.9(9.4)$ & $61.0(9.8)$ & $61.9(9.9)$ & $60.9(9.7)$ \\
\hline Mean (SD) body mass index $\left(\mathrm{kg} / \mathrm{m}^{2}\right)$ & $25.6(3.2)$ & $25.6(3.3)$ & $25.8(3.4)$ & $26.4(3.6)$ \\
\hline Mean (SD) height $(\mathrm{cm})$ & $177.4(6.7)$ & $177.2(6.6)$ & $177.1(6.7)$ & $177.2(6.8)$ \\
\hline \multicolumn{5}{|l|}{ Mean (SD) nutrient intake: } \\
\hline Energy $(\mathrm{kcal} / \mathrm{d})$ & $2513(795)$ & 2567 (769) & $2718(796)$ & $3111(915)$ \\
\hline Calcium (mg/d) & $1239(390)$ & $1420(363)$ & $1624(393)$ & $1931(493)$ \\
\hline Phosphorus (mg/d) & $1917(297)$ & $2043(280)$ & $2174(295)$ & $2378(355)$ \\
\hline
\end{tabular}


Table 1 (continued)

\begin{tabular}{|c|c|c|c|c|}
\hline \multirow[b]{2}{*}{ Characteristics } & \multicolumn{4}{|c|}{ Categories of daily milk intake } \\
\hline & $<1$ glass $(<200 \mathrm{~g} / \mathrm{d})$ & $1-2$ glasses $(200-399 \mathrm{~g} / \mathrm{d})$ & $2-3$ glasses $(400-599 \mathrm{~g} / \mathrm{d})$ & $\geq 3$ glasses $(\geq 600 \mathrm{~g} / \mathrm{d})$ \\
\hline Vitamin D (mg/d) & $6.1(2.9)$ & $6.6(2.9)$ & $7.1(2.8)$ & $7.7(3.2)$ \\
\hline Retinol (mg/d) & $1.18(0.97)$ & $1.24(0.87)$ & $1.28(0.72)$ & $1.35(0.84)$ \\
\hline Protein $(\mathrm{g} / \mathrm{d})$ & $98.3(14.8)$ & $101.5(14.0)$ & $104.9(14.1)$ & $110.9(15.3)$ \\
\hline Total fat $(\mathrm{g} / \mathrm{d})$ & $89.6(15.7)$ & $89.2(14.5)$ & $89.3(14.9)$ & $89.2(15.6)$ \\
\hline Saturated fat $(\mathrm{g} / \mathrm{d})$ & $40.2(9.6)$ & $40.5(9.0)$ & $41.3(9.4)$ & $42.2(10.0)$ \\
\hline Alcohol (g/d) & $16.1(22.8)$ & $12.4(17.5)$ & $11.6(21.5)$ & $11.3(20.5)$ \\
\hline Metabolic equivalents (kcal/kg and hour) & $41.2(4.8)$ & $41.4(4.8)$ & $41.8(5.0)$ & $42.3(5.3)$ \\
\hline Calcium supplement use & $1930(10.5)$ & $1101(10.2)$ & $833(9.3)$ & $576(8.1)$ \\
\hline Vitamin D supplement use & $2542(13.8)$ & $1521(14.0)$ & $1156(12.9)$ & $834(11.7)$ \\
\hline \multicolumn{5}{|l|}{ Educational level: } \\
\hline$\leq 9$ years & $11822(64.3)$ & $7324(67.8)$ & $6663(74.9)$ & $5553(78.4)$ \\
\hline $10-12$ years & $2954(16.1)$ & $1576(14.6)$ & $1029(11.6)$ & $714(10.1)$ \\
\hline$>12$ years & $3551(19.3)$ & $1864(17.2)$ & $1166(13.1)$ & $787(11.1)$ \\
\hline other & $71(0.4)$ & $45(0.4)$ & $33(0.4)$ & $31(0.4)$ \\
\hline \multicolumn{5}{|l|}{ Charlson comorbidity: } \\
\hline 0 & $15836(85.8)$ & 8975 (82.8) & 7262 (81.3) & $5809(81.7)$ \\
\hline 1 & $1865(10.1)$ & $1304(12.0)$ & 1148 (12.9) & $885(12.4)$ \\
\hline$\geq 2$ & $758(4.1)$ & $562(5.2)$ & $517(5.8)$ & $418(5.9)$ \\
\hline Ever cortisone use & $753(4.1)$ & $456(4.2)$ & $386(4.3)$ & $318(4.5)$ \\
\hline \multicolumn{5}{|l|}{ Smoker status: } \\
\hline Current & $4365(24.0)$ & $2419(22.6)$ & $2284(26.0)$ & $2041(29.1)$ \\
\hline Former & $7513(41.2)$ & $4120(38.5)$ & 3209 (36.6) & $2573(36.7)$ \\
\hline Never & $6347(34.8)$ & $4160(38.9)$ & $3286(37.4)$ & $2394(34.2)$ \\
\hline Living alone & $3116(16.9)$ & $1877(17.3)$ & $1646(18.4)$ & $1462(20.6)$ \\
\hline
\end{tabular}




\begin{tabular}{|c|c|c|c|c|c|}
\hline \multirow[b]{2}{*}{ Variables } & \multicolumn{4}{|c|}{ Categories of daily milk intake } & \multirow[b]{2}{*}{$\begin{array}{c}\text { Continuous (per } 200 \\
\text { g) }\end{array}$} \\
\hline & $<1$ glass $(<200 \mathrm{~g} / \mathrm{d})$ & $\begin{array}{c}\text { 1-2 glasses (200-399 } \\
\text { g/d) }\end{array}$ & $\begin{array}{c}\text { 2-3 glasses (400-599 } \\
\mathrm{g} / \mathrm{d})\end{array}$ & $\geq 3$ glasses $(\geq 600 \mathrm{~g} / \mathrm{d})$ & \\
\hline \multicolumn{6}{|l|}{ Swedish Mammography Cohort } \\
\hline \multicolumn{6}{|l|}{ Total mortality: } \\
\hline No of deaths & 5422 & 5830 & 3150 & 1139 & 15541 \\
\hline Person years of follow-up & 476485 & 444724 & 229648 & 80961 & 1231818 \\
\hline Rate/1000 person years $\dagger$ & 10.7 & 12.6 & 15.4 & 17.7 & 12.6 \\
\hline Age adjusted HR $(95 \% \mathrm{Cl})$ & 1.00 (reference) & $1.30(1.25$ to 1.35$)$ & $1.83(1.75$ to 1.91$)$ & 2.20 (2.06 to 2.35 ) & $1.18(1.16$ to 1.20$)$ \\
\hline Multivariable adjusted $\mathrm{HR}(95 \% \mathrm{Cl}) \ddagger$ & 1.00 (reference) & $1.21(1.16$ to 1.25$)$ & $1.60(1.53$ to 1.68$)$ & $1.93(1.80$ to 2.06$)$ & $1.15(1.13$ to 1.17$)$ \\
\hline \multicolumn{6}{|l|}{ Cardiovascular mortality: } \\
\hline No of deaths & 1904 & 1989 & 1030 & 355 & 5278 \\
\hline Person years of follow-up & 476485 & 444724 & 229648 & 80961 & 1231818 \\
\hline Rate/1000 person years $\dagger$ & 3.6 & 4.3 & 5.3 & 6.2 & 4.3 \\
\hline Age adjusted $\mathrm{HR}(95 \% \mathrm{Cl})$ & 1.00 (reference) & $1.26(1.18$ to 1.34$)$ & 1.85 (1.71 to 1.99$)$ & 2.19 (1.96 to 2.46$)$ & $1.20(1.16$ to 1.23$)$ \\
\hline Multivariable adjusted $\mathrm{HR}(95 \% \mathrm{Cl}) \ddagger$ & 1.00 (reference) & $1.16(1.09$ to 1.24$)$ & 1.59 (1.47 to 1.73$)$ & 1.90 (1.69 to 2.14$)$ & $1.15(1.12$ to 1.19$)$ \\
\hline \multicolumn{6}{|l|}{ Cancer mortality: } \\
\hline No of deaths & 1412 & 1196 & 488 & 187 & 3283 \\
\hline Person years of follow-up & 476485 & 444724 & 229648 & 80961 & 1231818 \\
\hline Rate/1000 person years $\dagger$ & 2.8 & 2.6 & 2.4 & 2.8 & 2.7 \\
\hline Age adjusted $\mathrm{HR}(95 \% \mathrm{Cl})$ & 1.00 (reference) & $1.11(1.02$ to 1.19$)$ & 1.24 (1.12 to 1.37$)$ & $1.55(1.33$ to 1.80$)$ & 1.09 (1.05 to 1.13$)$ \\
\hline Multivariable adjusted $\mathrm{HR}(95 \% \mathrm{Cl}) \ddagger$ & 1.00 (reference) & 1.07 (0.99 to 1.15$)$ & $1.16(1.04$ to 1.29$)$ & 1.44 (1.23 to 1.69$)$ & 1.07 (1.02 to 1.11$)$ \\
\hline \multicolumn{6}{|l|}{ Any fracture: } \\
\hline No of fractures & 7080 & 6317 & 2912 & 943 & 17252 \\
\hline Person years of follow-up & 424857 & 402138 & 210610 & 75231 & 1112837 \\
\hline Rate/1000 person years $\dagger$ & 16.0 & 15.4 & 15.0 & 15.1 & 15.5 \\
\hline Age adjusted HR $(95 \% \mathrm{Cl})$ & 1.00 (reference) & $1.08(1.04$ to 1.11$)$ & 1.17 (1.12 to 1.22$)$ & $1.16(1.08$ to 1.24$)$ & $1.02(1.00$ to 1.03$)$ \\
\hline Multivariable adjusted $\mathrm{HR}(95 \% \mathrm{Cl}) \ddagger$ & 1.00 (reference) & $1.07(1.04$ to 1.11$)$ & $1.16(1.11$ to 1.21$)$ & $1.16(1.08$ to 1.25$)$ & $1.02(1.00$ to 1.04$)$ \\
\hline \multicolumn{6}{|l|}{ Hip fracture: } \\
\hline No of fractures & 1584 & 1620 & 808 & 247 & 4259 \\
\hline Person years of follow-up & 468603 & 436885 & 225969 & 79838 & 1211295 \\
\hline Rate/1000 person years $\dagger$ & 3.1 & 3.6 & 4.1 & 4.2 & 3.5 \\
\hline Age adjusted $\mathrm{HR}(95 \% \mathrm{Cl})$ & 1.00 (reference) & 1.24 (1.16 to 1.33$)$ & $1.69(1.55$ to 1.85$)$ & 1.76 (1.54 to 2.02$)$ & $1.11(1.08$ to 1.15$)$ \\
\hline Multivariable adjusted $\mathrm{HR}(95 \% \mathrm{Cl}) \ddagger$ & 1.00 (reference) & 1.19 (1.11 to 1.28$)$ & $1.55(1.41$ to 1.69$)$ & $1.60(1.39$ to 1.84$)$ & 1.09 (1.05 to 1.13$)$ \\
\hline \multicolumn{6}{|l|}{ Cohort of Swedish Men } \\
\hline \multicolumn{6}{|l|}{ Total mortality: } \\
\hline No of deaths & 3468 & 2501 & 2347 & 1796 & 10112 \\
\hline Person years of follow-up & 221381 & 127248 & 103049 & 82415 & 534094 \\
\hline Rate/1000 person years $\dagger$ & 18.2 & 18.3 & 19.6 & 20.7 & 18.9 \\
\hline Age adjusted $\mathrm{HR}(95 \% \mathrm{Cl})$ & 1.00 (reference) & $1.00(0.95$ to 1.05$)$ & 1.07 (1.02 to 1.13$)$ & $1.13(1.07$ to 1.19$)$ & $1.03(1.02$ to 1.05$)$ \\
\hline Multivariable adjusted $\mathrm{HR}(95 \% \mathrm{Cl}) \ddagger$ & 1.00 (reference) & 0.99 (0.94 to 1.05$)$ & 1.05 (1.00 to 1.11$)$ & $1.10(1.03$ to 1.17$)$ & $1.03(1.01$ to 1.04$)$ \\
\hline \multicolumn{6}{|l|}{ Cardiovascular mortality: } \\
\hline No of deaths & 1468 & 1161 & 1098 & 841 & 4568 \\
\hline Person years of follow-up & 221381 & 127248 & 103049 & 82415 & 534094 \\
\hline Rate/1000 person years $\dagger$ & 7.9 & 8.4 & 9.0 & 9.6 & 8.6 \\
\hline Age adjusted HR $(95 \% \mathrm{Cl})$ & 1.00 (reference) & $1.06(0.98$ to 1.15$)$ & $1.14(1.05$ to 1.23$)$ & 1.21 (1.11 to 1.32$)$ & 1.05 (1.03 to 1.07$)$ \\
\hline Multivariable adjusted $\mathrm{HR}(95 \% \mathrm{Cl}) \ddagger$ & 1.00 (reference) & 1.04 (0.96 to 1.12$)$ & $1.10(1.01$ to 1.19$)$ & $1.16(1.06$ to 1.27$)$ & 1.05 (1.03 to 1.07$)$ \\
\hline \multicolumn{6}{|l|}{ Cancer mortality: } \\
\hline No of deaths & 1077 & 704 & 616 & 484 & 2881 \\
\hline Person years of follow-up & 221381 & 127248 & 103049 & 82415 & 534094 \\
\hline
\end{tabular}


Table 2 (continued)

\begin{tabular}{|c|c|c|c|c|c|}
\hline \multirow[b]{2}{*}{ Variables } & \multicolumn{4}{|c|}{ Categories of daily milk intake } & \multirow[b]{2}{*}{$\begin{array}{c}\text { Continuous (per } 200 \\
\text { g) }\end{array}$} \\
\hline & $<1$ glass $(<200 \mathrm{~g} / \mathrm{d})$ & $\begin{array}{c}\text { 1-2 glasses (200-399 } \\
\mathrm{g} / \mathrm{d})\end{array}$ & $\begin{array}{c}\text { 2-3 glasses (400-599 } \\
\mathrm{g} / \mathrm{d})\end{array}$ & $\geq 3$ glasses $(\geq 600 \mathrm{~g} / \mathrm{d})$ & \\
\hline Rate/1000 person years $\dagger$ & 5.5 & 5.2 & 5.4 & 5.6 & 5.4 \\
\hline Age adjusted HR $(95 \% \mathrm{Cl})$ & 1.00 (reference) & $0.95(0.87$ to 1.05$)$ & 0.97 (0.88 to 1.07$)$ & $1.03(0.92$ to 1.14$)$ & $1.00(0.98$ to 1.03$)$ \\
\hline Multivariable adjusted $\mathrm{HR}(95 \% \mathrm{Cl}) \ddagger$ & 1.00 (reference) & 0.97 (0.88 to 1.07$)$ & 0.97 (0.87 to 1.07$)$ & $1.01(0.90$ to 1.13$)$ & $0.99(0.97$ to 1.02$)$ \\
\hline \multicolumn{6}{|l|}{ Any fracture: } \\
\hline No of fractures & 2095 & 1326 & 1095 & 863 & 5379 \\
\hline Person years of follow-up & 211554 & 121162 & 98290 & 78355 & 509361 \\
\hline Rate/1000 person years $\dagger$ & 10.5 & 10.7 & 10.5 & 10.8 & 10.6 \\
\hline Age adjusted HR (95\% Cl) & 1.00 (reference) & $1.02(0.95$ to 1.10$)$ & 1.01 (0.94 to 1.09$)$ & 1.03 (0.96 to 1.12$)$ & $1.01(1.00$ to 1.03$)$ \\
\hline Multivariable adjusted $\mathrm{HR}(95 \% \mathrm{Cl}) \ddagger$ & 1.00 (reference) & $1.02(0.96$ to 1.10$)$ & $1.01(0.93$ to 1.08$)$ & $1.03(0.94$ to 1.11$)$ & $1.01(0.99$ to 1.03$)$ \\
\hline \multicolumn{6}{|l|}{ Hip fracture: } \\
\hline No of fractures & 439 & 309 & 318 & 200 & 1266 \\
\hline Person years of follow-up & 219925 & 126241 & 102126 & 81755 & 530047 \\
\hline Rate/1000 person years $\dagger$ & 2.4 & 2.3 & 2.7 & 2.3 & 2.4 \\
\hline Age adjusted HR (95\% Cl) & 1.00 (reference) & $0.95(0.82$ to 1.10$)$ & $1.12(0.96$ to 1.29$)$ & $0.97(0.82$ to 1.15$)$ & $1.02(0.98$ to 1.06$)$ \\
\hline Multivariable adjusted $\mathrm{HR}(95 \% \mathrm{Cl}) \ddagger$ & 1.00 (reference) & $0.95(0.82$ to 1.11$)$ & $1.13(0.97$ to 1.31$)$ & $1.01(0.85$ to 1.20$)$ & $1.03(0.99$ to 1.07$)$ \\
\hline
\end{tabular}

$\mathrm{HR}=$ hazard ratio.

* $\mathrm{Had}$ access to repeat exposure information; exposures and covariates were treated as cumulative averages.

†Age standardised rates, number of cases per 1000 person years at risk.

$\ddagger$ Adjusted for age, body mass index, height, total energy intake, total alcohol intake, healthy dietary pattern, calcium and vitamin D supplementation, ever use of cortisone, educational level, living alone, physical activity level estimated as metabolic equivalents, smoking status, and Charlson's comorbidity index; and in women additionally for use of oestrogen replacement therapy and nulliparity. 


\section{Figures}

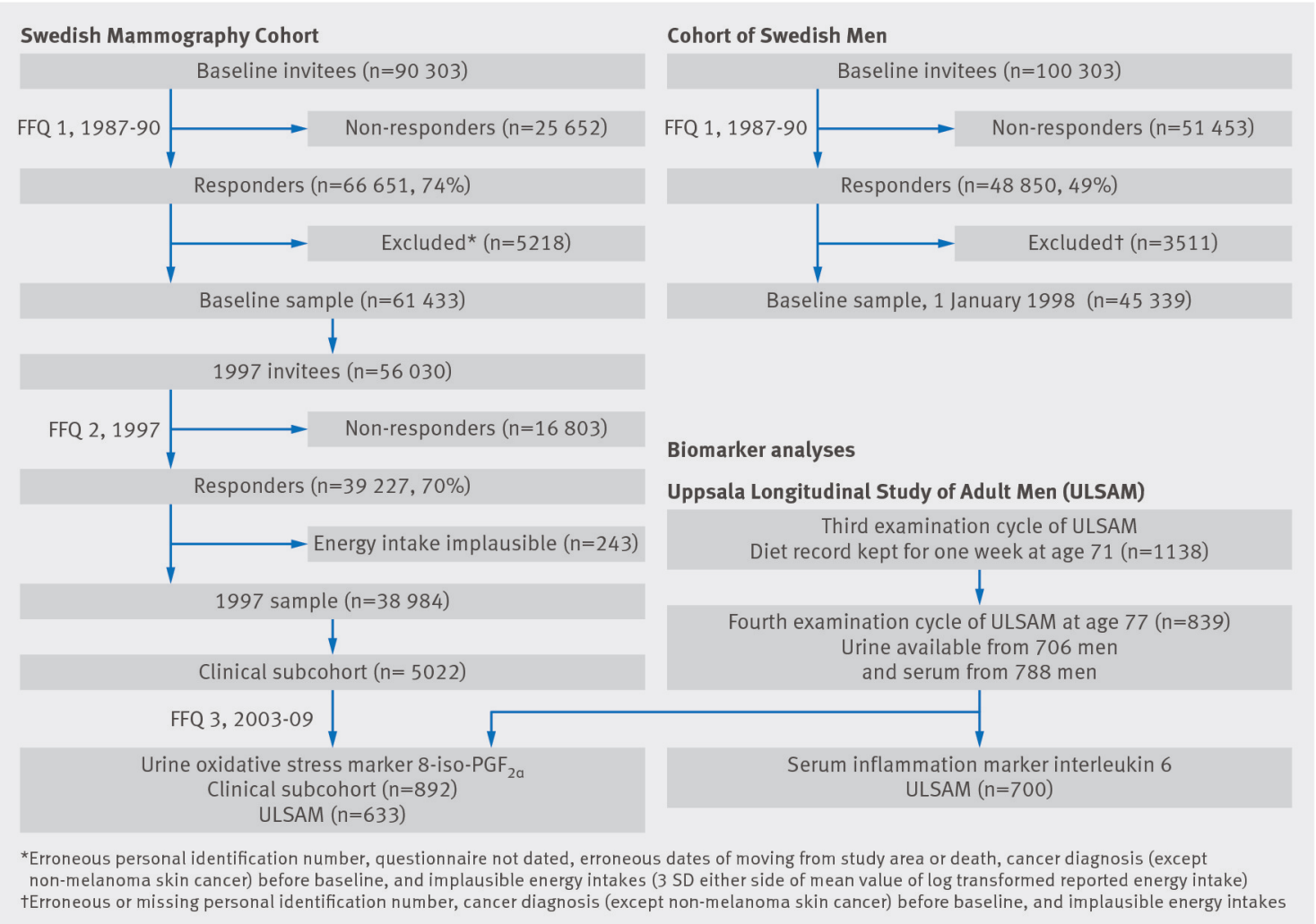

Fig 1 Flow chart of study samples 

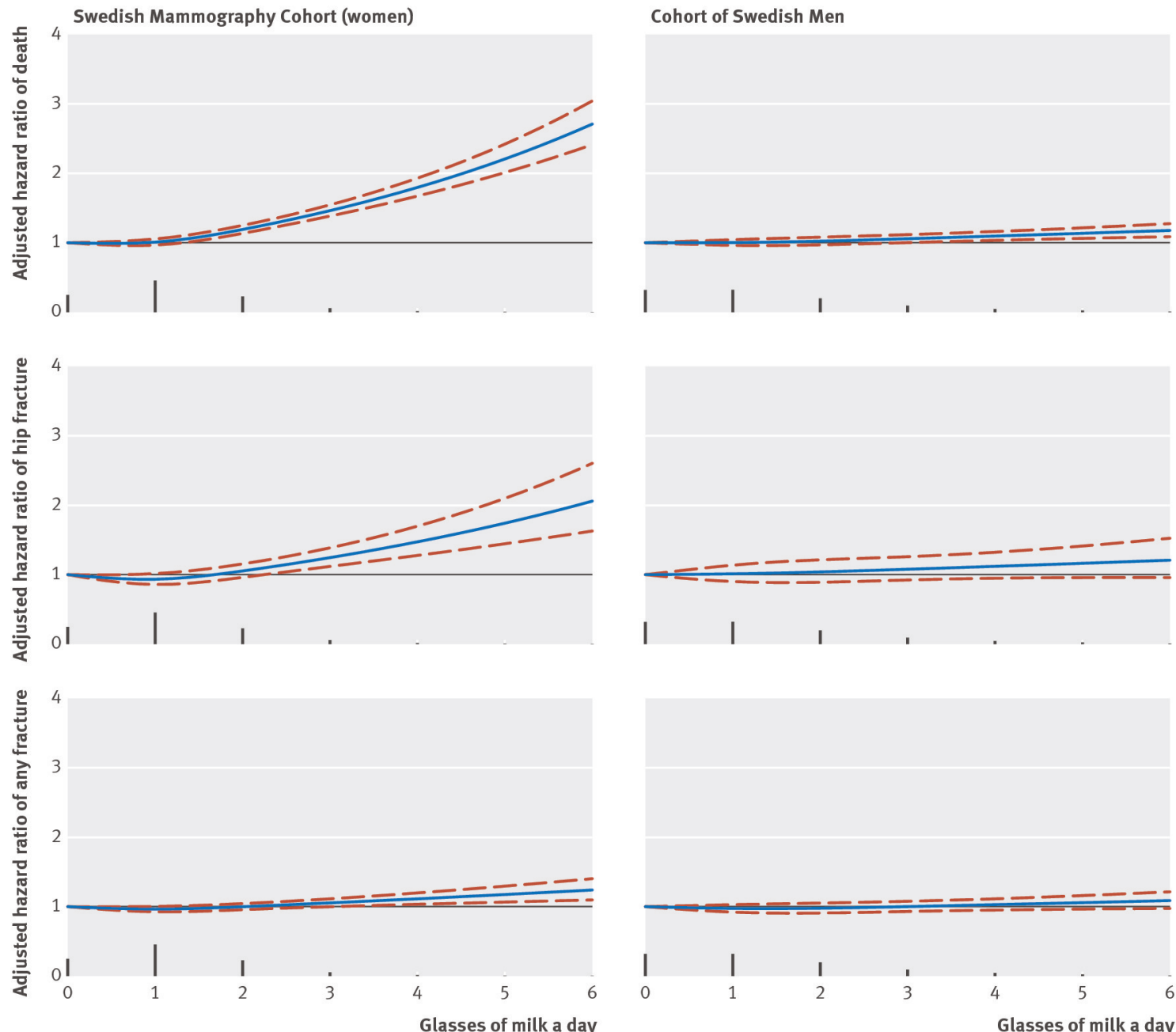

Fig 2 Sex specific multivariable adjusted spline curves of relation between milk intake with time to death from all causes, hip fracture, and any type of fracture. Covariates were age, total energy intake, body mass index, height, educational level, living alone, calcium supplementation, vitamin D supplementation, ever use of cortisone, healthy dietary pattern, physical activity, smoking status, and Charlson's comorbidity index. The spike plot represents the distribution of milk intake. One glass of milk corresponds to $200 \mathrm{~g}$ 

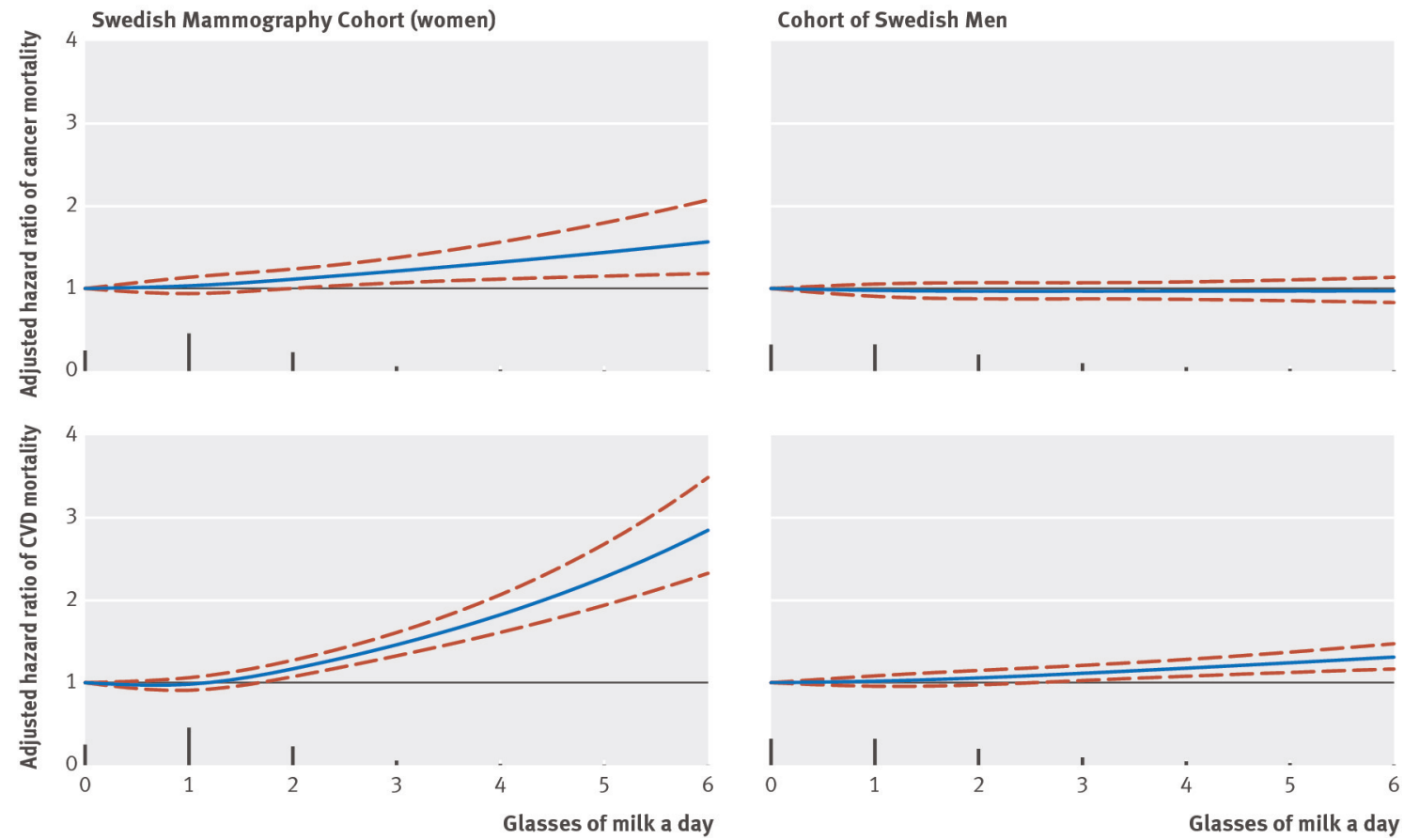

Fig 3 Sex specific multivariable adjusted spline curves of relation between milk intake with time to death from all cancer and cardiovascular disease (CVD). Covariates were age, total energy intake, body mass index, height, educational level, living alone, calcium supplementation, vitamin D supplementation, ever use of cortisone, healthy dietary pattern, physical activity, smoking status, and Charlson's comorbidity index. The spike plot represents the distribution of milk intake. One glass of milk corresponds to $200 \mathrm{~g}$ 

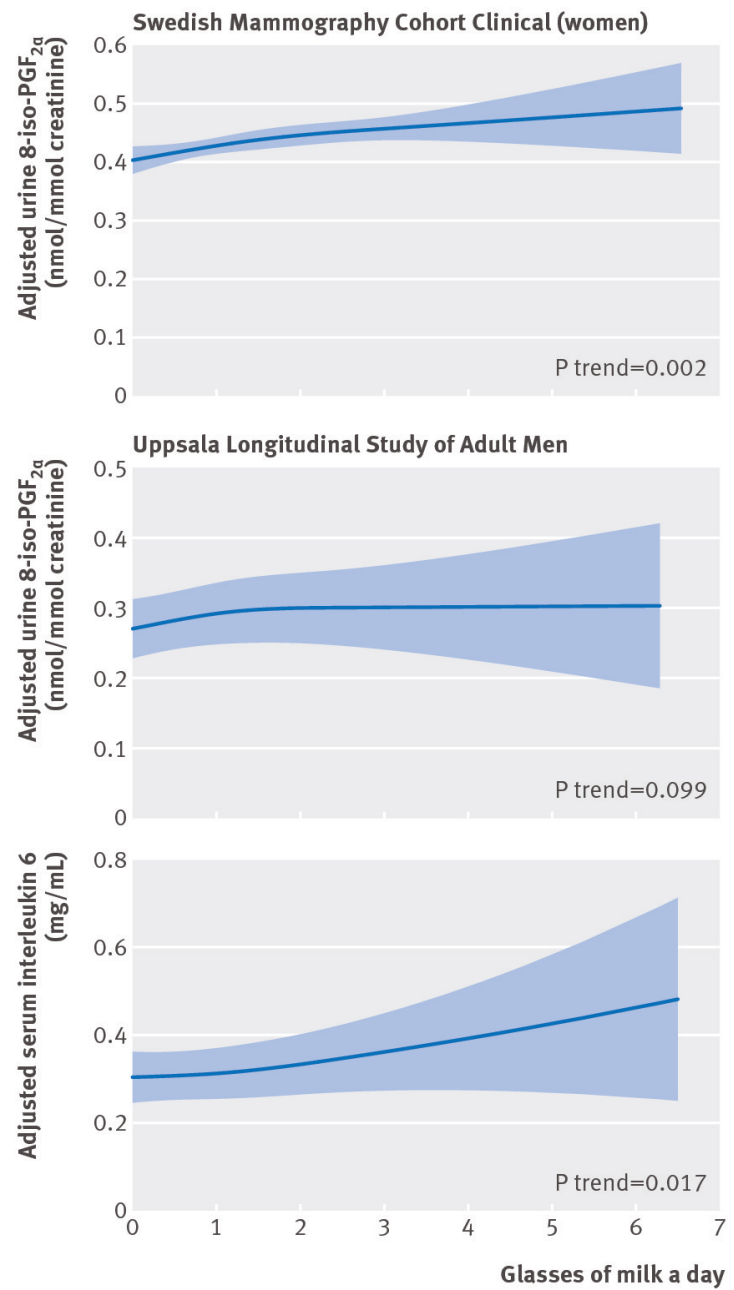

Fig 4 Adjusted predictions of urine log(8-iso-PGF2a), a marker of oxidative stress, in 892 women (based on cross sectional data, mean age 70 years) and 700 men, and serum log (interleukin 6), a marker of inflammation, in 633 men after cubic-spline regression with milk consumption. Data for men are based on milk consumption assessed at age 71 years and measurement of inflammatory markers at age 77 years. Covariates were age, body mass index, energy intake, education, smoking status, and physical activity. One glass of milk corresponds to $200 \mathrm{~g}$ 